- Dentists treating patients with autistic spectrum disorder (ASD) should be aware of the high levels of self-injurious behaviour within this group.

- Exfoliation of a deciduous tooth with an intact root warrants further investigation.

- Unexplained dental pain in a child with autism may be due to self-injury.

\title{
Autoextraction in a child with autistic spectrum disorder
}

\author{
M. Ross-Russell ${ }^{1}$ and P. Sloan ${ }^{2}$
}

Many children with mild/moderate autistic spectrum disorder (ASD) receive care in general dental practice. We report a seven year old boy with ASD presenting with dental pain who auto-extracted one of his deciduous canines. Children with ASD may have hyposensitivity to pain and can exhibit unusual forms of self-injurious behaviour.

\section{INTRODUCTION}

Autistic Spectrum Disorder (ASD) is a disorder of behaviour, socialisation and communication. Sufferers may receive their dental care in general dental practice or in community clinics. In general, patients with ASD do not exhibit any specific dental findings ${ }^{1}$ and have a low caries rate. ${ }^{2}$ The only truly unique oral findings are wounds resulting from self-injurious behaviour (SIB)..$^{3}$ It has been reported that as many as $70 \%$ of autistic patients may show selfinjury at some time in their lives, ${ }^{4}$ but this is generally seen in more severely affected individuals and can take many forms such as head banging, scratching, bruising and biting. Autoextraction of teeth is an unusual form of SIB and is rarely seen in children with ASD. We report a case of a young child with mild ASD who presented with unexplained dental pain and who subsequently went on to extract his own lower right deciduous canine tooth (73).

\section{CASE REPORT}

A seven-year-old boy, who had been a patient of the community dental service for the last three years, presented with dental pain. His medical history revealed autistic spectrum disorder (ASD) and occasional eczema. Initially, dental examination had only been possible with him sitting on his

\footnotetext{
${ }^{1 *}$ Clinical Head of Community Dental Service, Community Dental Department, Princess of Wales Hospital, Lynn Road, Ely, CB6 1DN; ${ }^{2}$ Professor of Oral Pathology, University Dental Hospital of Manchester, Higher Cambridge Street, Manchester M15 6FH.

${ }^{*}$ Correspondence to: Dr Maria Ross-Russell Email:maria.ross-russell@southcambs-pct.nhs.uk

\section{Refereed Paper}

Received 17.11.03; Accepted 10.05.04

doi: 10.1038/sj.bdj.4812250

(๑) British Dental Journal 2005; 198: 473-474
}

mother's knee, but over the three years he had grown in confidence and was now happy to be examined. No dental treatment had been necessary before this episode of care.

He had been born at term and during his early childhood had repeated ear infections. By two years his language was not developing well and he had a very limited vocabulary. He was also slow to sit and walk. Grommet surgery did not help with his speech and he developed non-verbal communication, such as pointing. A diagnosis of disordered language was made, but the development of further problems with social interactions and communication led to a diagnosis of ASD when he was six years old. He has also demonstrated SIB in the form of head banging. However, he remained only mildly affected and continued in mainstream school.

He was brought to the clinic complaining of pain of about one week's duration that was increasing in intensity. The pain was present most of the time and was not sensitive to hot, cold or sweet stimulus. Clinical examination did not reveal any evidence of caries or infection in this area. It did, however, reveal a need for sealant restorations in upper first permanent molars (16 and 26) and fissure sealants in lower first permanent molars (36 and 46).

Within 24 hours the patient was again back at the clinic, as the pain had not resolved with ibuprofen, and by this time his lower right deciduous canine (83) was very slightly mobile. An OPG showed no alveolar bone loss, normal root anatomy of 83, and 33 lying close to the border of the mandible with only crown formation completed. By the next day the patient had extracted his lower 83 (Fig. 1), witnessed by his mother. He claimed it had been 'itching'

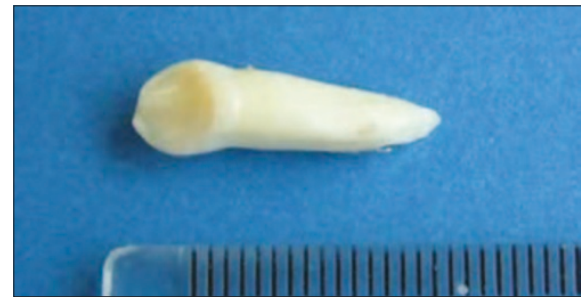

Fig. 1 Autoextracted lower right deciduous canine tooth (83).

him until he got it out. The socket looked completely normal and the pain resolved immediately. The mother gave permission for the tooth to be sent to the University Dental Hospital of Manchester for further investigation, and in particular to exclude the diagnosis of hypophosphatasia.

Further appointments to restore upper first permanent molars (16 and 26) and fissure seal lower first permanent molars (36 and 46) were successful and no further pain was experienced.

\section{DISCUSSION}

We describe a case of unexplained dental pain in an autistic boy who went on to selfextract a deciduous tooth. It has been reported that autistic children frequently have atypical responses to sensory stimuli, such as an apparent hyposensitivity to pain. ${ }^{5}$ In this case the patient did experience some pain - presumably as a response to his attempts to pull the tooth out - but not enough to deter him from autoextraction.

There have been several reports of autoextraction in the literature, but most of these have been in adults. One 29-year-old patient with a diagnosis of a psychotic illness, who extracted both upper canine teeth, reported that the act decreased his tension and was painless. ${ }^{6}$ Another 27year-old psychiatric patient attempted to 


\begin{tabular}{ll} 
Table 1 Causes of exfoliation of deciduous teeth with complete roots \\
\hline Autoextraction & Autism \\
& Genetic syndromes involving CNS ${ }^{10}$ \\
& Congenital disorders of CNS ${ }^{10}$ \\
\hline Physical trauma & Accidental trauma \\
& Non-accidental injury \\
& Munchhausen by proxy \\
\hline Defective cementum formation & Hypophosphatasia \\
\hline Inflammatory destruction of periodontium & Papillon-Lefevre syndrome \\
due to impaired host defence & Chediak-Higashi syndrome \\
& Leukocyte Adherence Deficiency \\
& Prepubertal (aggressive) periodontitis \\
& HIV infection \\
& Neutropaenia \\
& Type I diabetes \\
\hline Malignant destruction of periodontium & Leukaemia \\
and alveolus & Langerhans cell histiocytosis \\
& Neoplasms in the jawbone \\
\end{tabular}

extract 12 permanent posterior teeth with pliers, but caused multiple crown fractures and all roots had to be removed surgically. ${ }^{7}$ Those reports which describe children include one 11 year old girl who caused traumatic gingival ulceration whilst undergoing orthodontic treatment. ${ }^{8}$ In common with our patient she described an 'itchy' feeling and had an uncontrollable urge to scratch the area. Another report of selfextraction in children describes six patients with familial dysautonomia. ${ }^{9}$ There were 11 self-extracted teeth of which five were from the primary dentition. These authors conclude that self-extraction of teeth was mostly unintentional. In three patients it occurred during play while pulling a toy held tightly between the teeth. We think it is unlikely that these teeth had the same root length as in this case.
Although there are a number of rare causes of deciduous tooth loss in children, ${ }^{10}$ nearly all of these are associated with significant alveolar bone loss (Table 1). In this case, the normal alveolar bone limits the differential diagnosis to two or three causes. Child abuse was felt very unlikely, as the child was brought to the clinic in pain before the tooth was lost and there were no other accompanying signs. Munchausen by proxy was discounted as the patient gave a history of extracting his own tooth. Hypophosphatasia was excluded following histopathological examination of the extracted tooth at the University Dental Hospital of Manchester. No abnormality of formation of the dental hard tissues was found and both cellular and acellular cementum were present in normal quantity. Resorption of the root apex cementum had just commenced.

\section{CONCLUSION}

A wide range of disorders may cause exfoliation of a deciduous tooth with an intact root. The occurrence should prompt a careful review of the clinical history, (including family history), thorough examination and where appropriate, special tests including radiology and laboratory investigations.

Those of us treating patients with ASD should be aware of the high levels of selfinjurious behaviour within this group. When faced with dental pain, which cannot be explained by more common causes such as caries or infection, we should consider trauma due to self-injurious behaviour in our differential diagnosis.

1. Kopel H M. The autistic child in dental practice. ASDC J Dent Child 1977; 44: 302-309.

2. Karen S, Skier J. Dental management of the autistic child. Spec Care Dentist 1985; 5: 20-23.

3. Armstrong D, Matt M. Autoextraction in an autistic dental patient: a case report. Spec Care Dentist 1999: 19: 72-74.

4. Howlin P. Behavioural techniques to reduce selfinjurious behaviour in children with autism. Acta Paedopsychiatrica 1993; 56: 75-84.

5. Mauk J E. Autism and pervasive development disorders. Pediatr Clin North Am 1993; 40: 567-579.

6. Walter-Ryan W G, Shirriff J R. Self-mutilation by tooth extraction. South Med J 1985; 78: 1519-1520.

7. Altom R L, DiAngelis A J. Multiple autoextractions: oral self-mutilation reviewed. Oral Surg Oral Med Oral Pathol 1989; 67: 271-274

8. Spencer R J, Haria S, Evans R D. Gingivitis artefacta - a case report of a patient undergoing orthodontic treatment. BrJ Orthodont 1999; 26: 93-96.

9. Mass $E_{1}$ Gadoth N. Oro-dental self-mutilation in familial dysautonomia. J Oral Pathol Med 1994; 23: 273-276.

10. Medina A C, Sogbe R, Gómez-Rey A M, Mata M Factitial oral lesions in an autistic paediatric patient. Int J Paediatr Dentist 2003; 13: 130-137. 